\title{
Review on Psychological Crowd Model Based on LeBon's Theory
}

\author{
Vahid Behtaji Siahkal Mahalleh, Hazlina Selamat*, Fargham Sandhu \\ Departement of Electrical Engineering, Universiti Teknologi Malaysia, \\ Center for Artificial Intelligence, Universiti Teknologi Malaysia, 81310, Johor Bahru, Malaysia \\ ${ }^{*}$ Corresponding author, e-mail: hazlina@utm.my
}

\begin{abstract}
Irrational crowds tend to adapt herd mentality, having group behaviour and high suggestion through interaction. It is important to see how an irrational crowd can be controlled to prevent undesirable crowd attitude. This paper reviews existing models and the controllers to provide a comprehensive study for crowd control. It focuses on a comprehensive analysis of the control of psychological crowd, modelled using LeBon's theory; which defines the crowd behaviour in terms of crowd attitude. The crowd attitude is defined in terms of suggestibility and prestige and the crowd interaction is defined in terms of the interaction of prestige and suggestibility, which is naturally unstable. A controller is required to achieve stability. In this paper several control approaches are described and the best control approach is highlighted. The results conclude, the best control approach is using multiple control agents, since the control effort is reduced and the stabilizing time is improved.
\end{abstract}

Keywords: psychological crowd, LeBon's theory, crowd attitude, multiple control agents

Copyright $@ 2017$ Universitas Ahmad Dahlan. All rights reserved.

\section{Introduction}

The catastrophic of a crowd is regularly cited as its most noticeable quality. Sociologists and psychologists started to investigate crowd violence as protests and riots became more frequent. Examples of crowd violence include, a riot at the Thai embassy in Cambodia in 2003, where people were injured and died; 90 spectators were arrested for disorderly conduct after the Oakland Raiders vanished the Super bowl in 2003; about 290 persons were arrested for riots at an anti-war protest in New York City in 2003 [1]. The study on crowd psychology attempts to investigate a psychological theory that can be applied for these incidents. It also studies similar processes of psychological behaviour that occurs in an organized political demonstration that turned into an irrational crowd or spontaneous riot following a football game. However, there are differences among these examples such as aims and characters that should not be overlooked. Therefore, the existing psychological theories for irrational crowds at work under all these events may be evaluated deeply. Theories of crowd behaviours have long evolved considerably. The ideas of crowd behaviour have been proposed by Le Bon's Suggestibility Theory and De-individuation Theory. These theories generate group mind models of crowd behaviors. It is important to know how modern-day thinking about crowd behaviors has derived from the group mind models. Consequently, the evolvement of crowd behavior ideas should be noted with consistency of certain themes. In this study, Le Bon's theory is highlighted for two fundamental reasons. The first reason is that Le Bon's theory is well-known [2-4] and had become prominent in many countries. The second reason, in the post-Mao period, the only attempt on crowd psychology was Le Bon's theory that has been considerably revivified among administrators, political elite and the general public. Accordingly, common and different themes are possible to be classified over various periods. The following sections interprete group mind theories and criticisms of crowd behaviors. 


\section{Group Mind Theory}

In this section the theory of crowd behaviours that are based on LeBon and existing criticisms on the crowd behavioural are discussed.

\subsection{LeBon's Theory}

The classic theories were proposed by LeBon (1908) and Freud (1921). They believed that the crowd behaviours were abnormal and pathological. Therefore, civilisation and consciousness of crowds is replaced by savage animal instincts, where the crowd keeps the unconscious mind of individuals. The individuals lose all sense of themselves when they enter the crowd and do not identify themselves as individuals with responsibility for their own actions, but become unidentified members of a group. These individuals achieve a sense of power and invincibility $[2,5]$. The first component of LeBon's theory states that the characteristic of a crowd is specifically varied in comparisons with the characteristic of individuals. This component is called the Law of Mental Unity of psychological crowds [2], which is like chemical elements when combined to make an entirely new material [6]. According to Le Bon, an individual in a psychological crowd is under hypnosis and accept easily the action of its surrounding persons. The second component is suggestibility. Suggestibility is a state of how easily a crowd act to any idea [7]. The third component is prestige, the level of influence that leaders have on the psychological crowds. Leaders with higher prestige have higher influence on the other members of the crowd. Prestige not only can turn a crowd into an irrational crowd but is necessary for an idea to propagate in a suggestible crowd. In other words, prestige and suggestibility need an action to spread through a crowd [8]. LeBon defines two types of prestige: acquired prestige and personal prestige. Acquired prestige is defined as the prestige associated with appointment to an authoritative position such as a judge, a soldier or royalty [2, 6, 9], whereas personal prestige is earned by individuals' charisma. One of the famous examples of personal prestige was that of Napolean's that can captivate people with his charisma. In fact, personal prestige is independent of leader's reputation [9]. The others components of Le Bon's theory are the remote factors that identify how ideas and belief propagate throughout a crowd [2]. These factors include traditions, degree of education and race [6]. The last components of LeBon's theory are the immediate factors that refer to external events that affect the propsgation of psychological effects such as riots in which an opinion takes shape and start to spread through a crowd [7]. Le Bon's theory demonstrates the importance of power in crowd behaviours and proves a significant factor in collective action [10-11]. In conclusion, LeBon's theory argued that individuals lose their personal rationality and revert to the animal instincts in the crowd [12]. However, in the following century, this idea was considered as speculative and it had enormous effects on attempts in sociology and psychology to illustrate crowd behaviour. The idea was picked up as experimental social psychology in some researches [8], [13-18]. The valid criticisms of Le Bon's theory are related to reduce self-conscious, which is unable to act in a natural way and increase chance of antisocial behaviour [12, 19]. LeBon's theory may downplay the social motives of crowd action [20]. Despite these criticisms, Le Bon's Theory is important to study because it had become prominent in many countries and in the post-Mao period, the only attempt on crowd psychology was Le Bon's theory that has been considerably revivified among administrators, political elite and the general public [2-4]. The aim of applying control techniques is to control the crowd such that it wills retrun the irrational crowd to an orderly and calm state. Hence, the crowd is assumed as irrational as LeBon interpreted. The following section concentrates on the mathematical psychological model based on LeBon's theory.

\subsection{Discrete-Time Model of Crowd Psychological Behavior Based on LeBon's Theory}

The mathematical model of the crowd psychological dynamics includes psychological factors such as prestige, attitude and suggestibility that depend on each other and are unstable. To benefit from what control system theory can offer to the study of crowd behavior, researchers have tried to capture the principles of LeBon's theory in a theoretic form. To start the abstraction of model, the psychological crowd is said to be included of individuals. This method emphasizes the ability of an individual to affect and act on its environment by social communications with other crowd members. Researches in [6-8], [21-23] have considered crowds in a queue while paying for groceries at a busy supermarket, waiting to use an ATM or seeking admission to an amusement park using the mathematical model of crowd psychological dynamics that is based 
on Le Bon's Theory. The state of each individual in the model is expressed by four signals, which are the prestige, attitude, delay of attitude and suggestibility of each individual as follows:

$$
\begin{aligned}
& \mathrm{p}_{\mathrm{i}}[\mathrm{k}+1]=\mathrm{c}_{\mathrm{p}} \mathrm{p}_{\mathrm{i}}[\mathrm{k}]+\mu_{\mathrm{pa}, \mathrm{i}}\left|\mathrm{a}_{\mathrm{i}}[\mathrm{k}]\right| \\
& \mathrm{a}_{\mathrm{i}}[\mathrm{k}+1]=\mathrm{c}_{\mathrm{a}} \mathrm{a}_{\mathrm{i}}[\mathrm{k}]+\mu_{\mathrm{apa}, \mathrm{i}} \mathrm{s}_{\mathrm{i}}^{2}[\mathrm{k}] \sum_{\mathrm{j} \in \mathrm{N}_{\mathrm{i}}} \mathrm{d}_{\mathrm{i}, \mathrm{j}} \mathrm{p}_{\mathrm{j}}[\mathrm{k}] \mathrm{a}_{\mathrm{j}}[\mathrm{k}] \\
& \mathrm{b}_{\mathrm{i}}[\mathrm{k}+1]=\mathrm{a}_{\mathrm{i}}[\mathrm{k}] \\
& \mathrm{s}_{\mathrm{i}}[\mathrm{k}+1]=\mu_{\mathrm{s}, \mathrm{i}} \mathrm{S}_{\mathrm{def}} \alpha^{\mathrm{c}_{\mathrm{s}} \beta_{\mathrm{i}}[\mathrm{k}]} \\
& \beta_{\mathrm{i}}[\mathrm{k}]=\mu_{\mathrm{sa}, \mathrm{i}}\left(\mathrm{a}_{\mathrm{i}}[\mathrm{k}]-\mathrm{b}_{\mathrm{i}}[\mathrm{k}]\right)^{2}+\mu_{\mathrm{sap}, \mathrm{i}} \sum_{\mathrm{j} \in \mathrm{N}_{\mathrm{i}}} \mathrm{d}_{\mathrm{i}, \mathrm{j}} \mathrm{p}_{\mathrm{j}}[\mathrm{k}]\left|\mathrm{a}_{\mathrm{j}}[\mathrm{k}]\right|+ \\
& \quad \mu_{s s p, i} \sum_{j \in N_{i}} d_{i, j} p_{j}[k]\left(s_{j}[k]-s_{i}[k]\right)
\end{aligned}
$$

In Equation (1), $\mathrm{p}_{\mathrm{i}}[\mathrm{k}]$ is the prestige of the $\mathrm{i}^{\text {th }}$ individual at time $\mathrm{k}$. The prestige constant $\left(c_{p}\right)$ influences the value of prestige toward zero [6-8], [21-23]. The power of a prestige is made by the actions of individual (i) that it is shown by the parameter $\mu_{\mathrm{pa}, \mathrm{i}}$. In Equation (2), $\mathrm{a}_{\mathrm{i}}[\mathrm{k}]$ is the action of the $i^{\text {th }}$ individual at time $\mathrm{k}$. The attitude constant $\left(c_{\mathrm{a}}\right)$ influences the speed of diminishing the attitude value while the prestige value of individual (i) inclines toward zero [8]. As an interacting individuals, $\left(\mathrm{N}_{\mathrm{i}}\right)$ plays the role in their model [6]. Larger absolute values of attitude are assumed to be undesirable [9]. In Equation (3), $b_{i}[k]$ is the delayed value of action of the $i^{\text {th }}$ individual at time $\mathrm{k}$. In Equation (4), $\mathrm{s}_{\mathrm{i}}[\mathrm{k}]$ is the suggestibility of $\mathrm{i}^{\text {th }}$ individual at time $\mathrm{k}$. The suggestibility constant is $\left(\mathrm{c}_{\mathrm{s}}\right)$ and it influences the speed of diminishing of the suggestibility value [7]. The power of a suggestibility is made from the imitating actions of individual (i) which is taken from others (neighbours) shown by the parameter $\mu_{s, i}$ [8]. The default value of suggestibility is $s_{\text {def }}[6-8],[21-23]$. $\alpha$ is greater than one illustrating a constant growth. If the social excitation $\left(a_{i}(k)\right.$ and $p_{i}(k)$ to incline towards zero) are absent, the value of $s_{i}(k)$ inclines towards $s_{\text {def }} \times \mu_{s, i}$ [7-8]. In Equation (5), suggestibility is an exponential function of $\beta_{\mathrm{i}}[\mathrm{k}]$. Individual-dependent gains are determined by $\mu_{\mathrm{sa}, \mathrm{i}}, \mu_{\mathrm{ssp}, \mathrm{i}}, \mu_{\mathrm{sap}, \mathrm{i}}$ [7-8]. Changes in attitude and interactions with prestigious persons (from one time instant $(\mathrm{k})$ to the next $(\mathrm{k}+1)$ inclines to make a crowd more suggestible. This phenomenon is considered in [6-9], [21-23]. If individuals interacting members who are more suggestible, the suggestibility of individual i increases. Otherwise, it decreases [9]. The interaction between attitude and suggestibility in the model demonstrates the unstable nature of psychological crowds $[2,6]$. This phenomenon motivates the application of control system techniques to return the crowd to an orderly and calm state [6].

\section{Controlling the Dynamic Psychological Factors of the Psychological Crowd Model}

Various psychological crowd control schemes and their weakness are reviewed in this section. Control theories are applied to drive the psychological dynamic factors of the psychological crowd to a calm state, zero.

\subsection{Linear Controller Scheme}

Earlier schemes were based on the linearized model of the psychological crowd dynamics given in Equations (1)-(5). In these schemes, sensors and actuators were based on social nature $[6,25]$. The psychological factors such as suggestibility, attitude and prestige were observed by a person who played the role of a sensor. This person was called the "human sensor'. The input of the human sensor was one of the state variables of the psychological factor and the controller influenced the feedback states. The actuators were used to influence the observers through human actuators. For example, a teacher in a class influences the students to behave properly [6]. Among various states that define the behavior of an individual in a crowd, as given in equation (6) attitude is physically measured and used to control the crowd $[6,25]$.

$$
a_{i}[k+1]=c_{a} a_{i}[k]+\mu_{a p a, i} s_{i}^{2} \sum_{o_{j} \in N\left(O_{i}\right)} p_{j}[k] a_{j}[k]+u_{i}(k)
$$


In Equation (6), for any individual $i$ in the crowd, the control signal ' $u_{i}(k)$ ', represents the action of ith individual which has good steady state regulation, but weak transient performance. Furthermore, the controller forces the prestige of each individual to become negative, despite the fact that a slightly positive prestige is desired.

A Luenberger observer is possible for estimating the states, but due to model sensitivity to noise, other schemes using nonlinear models are more feasible [6], [22-24].

\subsection{Effect of Two Non-linear Controller Scheme on Group Social Behaviour}

Bergey, et al. (2007) and Spieser, et al. (2008) proposed a two non-linear controller schemes as given in Equations (7)-(9) [6, 22].

$$
\begin{aligned}
& \mathrm{u}_{\mathrm{i}}(\mathrm{k})=-\mathrm{a}_{\mathrm{i}}(\mathrm{k}) \\
& \mathrm{m}(\mathrm{k})=\min \left\{\arg \max _{\mathrm{i}}\left|\mathrm{a}_{\mathrm{i}}(\mathrm{k})\right|\right\} \\
& \mathrm{u}_{\mathrm{i}}(\mathrm{k})= \begin{cases}0 & \text { if } \mathrm{i} \neq \mathrm{m}(\mathrm{k}) \\
-\mathrm{a}_{\mathrm{i}}(\mathrm{k}) & \text { if } \quad \mathrm{i}=\mathrm{m}(\mathrm{k})\end{cases}
\end{aligned}
$$

In this scheme, Equation (7) shows that the control signal has negative attitudes for each person [6, 22]. The controller tries to make the attitude of each people zero at every time instant. In fact, the controller cancels out the attitude of each person at every time instant. The prestige values are negative when the Luenberger observer based linear plant is applied. Therefore, this issue is solved using nonlinear controller.

From the stabilization time viewpoint, the performance of the controller is better than the traditional Luenberger observer [6, 22]. But the nonlinear control scheme requires many resources, for example, $\mathrm{N}$ observers require $\mathrm{N}$ controllers $[6,22]$. Therefore, another nonlinear control scheme is suggested in Equations (8)-(9). Equation (8) shows that the controller only controls the most outspoken person who has the largest absolute value of attitude. The control signal is defined in Equation (9). The simulation's result of this control scheme shows the same behavior as the previous one (nonlinear control) without many resources [6].

In spite of the good performance of two nonlinear controllers and simple schemes, there were two following problems for nonlinear controllers' schemes [6, 22]. The first issue is the nonlinear controller scheme in Equations (7) and (9) cancel out the dynamic state of attitude Equation (2). This assumption contradictory to LeBon's theory of social group behavior. The second issue as indicated in Equation (9), is that human controller are scampered in the crowd controlling each individual at every time instant, requiring more energy. Therefore other control strategies are employed [21-23].

\subsection{One Control agent to Stabilize One-Dimensional Crowd}

This method explored the social group behavior and controller implementation [26-27]. Control agent was introduced as an authoritative figure (such as police officer, teacher, a security card etc.) that does not follow crowd mentality and had fair judgment. For example, children consider parents, police officers and teachers as traditional authoritative figure [28]. The control agent was able to sense all states of agents' psychological factors [21-23]. The control agents used their knowledge as well as LeBon's idea and influenced the crowd behaviors [21-23]. The characteristics of control agents are presented by Equations (10) to (12) [22].

$$
\begin{aligned}
& \mathrm{p}(\mathrm{k})=\hat{\mathrm{p}}>0 \\
& \mathrm{x}(\mathrm{k})=\mathrm{a}(\mathrm{k})=\mathrm{u}\left[\mathrm{p}_{1}(\mathrm{k}), \ldots \mathrm{p}_{\mathrm{n}}(\mathrm{k}), \mathrm{a}_{1}(\mathrm{k}), \ldots \mathrm{a}_{2}(\mathrm{k}), \mathrm{b}_{1}(\mathrm{k}), \ldots, \mathrm{b}_{\mathrm{n}}(\mathrm{k}), \mathrm{s}_{1}(\mathrm{k}), \ldots, \mathrm{s}_{\mathrm{n}}(\mathrm{k})\right] \\
& \mathrm{s}(\mathrm{k})=0
\end{aligned}
$$

In Equation (10) if the prestige is greater than zero, it means the control agent has constant influence on the behavior of the crowd. Equation (11) indicates, the control agent make decision based on the behavior of individuals in the crowd. In other word, the behaviors of individuals are predicated by the control agent. Equation (12) shows that the control agent is not 
influenced by suggestion. Therefore, the control agent has zero suggestibility value $(s=0)$ [2123]. In terms of a system perspective, a control agent is introduced to provide feedback to the system to achieve stability. In earlier works the performance of sensor and actuator were done by a person. The presented control agent was used to stabilize queues.

Spieser, et al. (2008) applied a simple queue to show how control signal propagates through members in a queue. The objective was to achieve zero state of two individuals at $\mathrm{k} \geq 2$ (crowd gets calm). In this work, the control agent was positioned at the beginning of the queue and it influenced each observer through observer to observer interaction. The propagation of control signal from one observer to another was modelled using equation (13) [22].

$$
u[k]=-\frac{a_{i}^{u}[k+1]}{a_{i}^{u}[k+1]}
$$

In Equation (13) the function $a_{i}^{\bar{u}}[k+i]$ is independent of the control signal and considered non zero $\left(\mathrm{a}_{\mathrm{i}}^{\overline{\mathrm{u}}}[\mathrm{k}+\mathrm{i}] \neq 0\right)$. The aim of this study was to find a serious of controllers to stabilize the crowd. The results concluded that if the attitude of the right most agents becomes zero for the interval $\mathrm{k} \geq \tilde{\mathrm{k}} \geq 0$, the attitude of each individual shall become zero. The results also showed a proportional relationship between control effort and queue's length and the time taken to stabilize the crowd. For optimal performance it was found that the time taken by control signal to propagate through the crowd must be minimum. This caused a limitation on the control of large crowd by a single agent. In this method, crowd stability law requires the measurement of each individual's attitude to stabilize the crowd, which is not suitable for large crowds. Similarly, the settling time becomes very large for a large crowd. This method is not so suitable. For large crowd, multi control agent scheme is used [21].

\subsection{Multi-Agent Controllers to Stabilize One-Dimensional Crowd}

In this method, multiple controllers were used to stabilize a 1D queue [21]. The approach used similar to single agent control approach [22]. In multiple agent control scheme the controllers were restricted to have coordinated approach to present control signal collisions between control agents [34]. For example, when the right most individual is as control agent, it should play a more active role in stabilizing the queue. Another advantage of multiple agent control scheme is reduction of the state variables required for control [23]. The mult iple agent control scheme requires each agent to control sequentially. For example, if in a crowd of five members $\left(X_{1}, O_{2}, X_{3}, O_{4}, X_{5}\right)$ with $\left(X_{1}, X_{3}, X_{5}\right)$ being the control agents, the control $X_{5}$ first applies the control signal, followed by $X_{3}$, while $X_{1}$ applies control signal after $X_{3}$. For simplicity the queue can be sub-divided into sub queues with control agents in each sub queues. In this case, the sub queues interaction becomes important. This method results into a new control law. Earlier research $[21,23]$ has shown that if any queue has even number of member, the division of that queue into sub queues, results into sub queues with interaction required. The propagation time taken by the control signal to propagate from one agent to the next is considered same for simplicity. In equal sub queues the attitude of the left most control agent is calculated using the attitude of the right agents is given by Equation (14).

$$
a_{n^{*}}\left[k+n^{*}\right]=a_{n^{*}}^{\overline{u^{1}}}\left[k+n^{*}\right]+a_{n^{*}}^{u^{1}}\left[k+n^{*}\right] u^{1}[k]
$$

In Equation (14), $a_{n^{*}}^{u^{1}}\left[k+n^{*}\right]$ is the dependent control signal and $a_{n^{*}}^{\overline{u^{1}}}\left[k+n^{*}\right]$ is the independent control signal. The dependent control signal $\mathrm{a}_{\mathrm{n}^{*}}^{\mathrm{u}^{1}}\left[\mathrm{k}+\mathrm{n}^{*}\right]$ is non zero. It is important to mention that the product of dependent and independent control signal $a_{n^{*}}^{u^{1}}\left[k+n^{*}\right], a_{n^{*}}^{\overline{u^{1}}}\left[k+n^{*}\right]$ as given in Equation (14) depends upon the entre state of the queue and not only one the sub queues. Similarly, in the same sub queue, the attitude of the right most agent is calculated using the attitude of the left agents is given by Equation (15).

$$
a_{\boldsymbol{n}^{*}+1}\left[k+\left(\boldsymbol{n}-\boldsymbol{n}^{*}\right)\right]=a_{\boldsymbol{n}^{*}+1}^{\overline{u^{2}}}\left[k+\left(\boldsymbol{n}-\boldsymbol{n}^{*}\right)\right]+a_{\boldsymbol{n}^{*}+1}^{u^{2}}\left[k+\left(\boldsymbol{n}-\boldsymbol{n}^{*}\right)\right] u^{2}[k]
$$

The term of dependent control signal is nonzero $a_{n^{*}+1}^{u^{2}}\left[k+\left(n-n^{*}\right)\right] \neq 0$. If the number of agents is odd, then unequal sub queues are created with left most sub queue being larger

Review on Psychological Crowd Model Based on LeBon's... (Vahid Behtaji Siahkal Mahalleh) 
than the right ones. The attitude of the right most agent in the right most sub queue is calculated using the attitude of the left most agent in the same sub queue using Equation (15), which is similar in both cases (Even and Odd). However, the attitude of the right most agent in the left sub queue is calculated from the left most agent in the same sub queue (Even and Odd) with few modification to Equation (14), which was used for even sub queues. In this case, the attitudes $\mathrm{a}_{\mathrm{n}^{*}}^{\mathrm{u}^{1}}\left[\mathrm{k}+\mathrm{n}^{*}\right]$ and $\mathrm{a}_{\mathrm{n}^{*}}^{\overline{\mathrm{u}^{1}}}\left[\mathrm{k}+\mathrm{n}^{*}\right]$ does not only depend upon the attitude of the left most agent in the same sub queue ( as in Equation 14) but also depends upon the prestige of the control agent of the right most agent in the right sub queue, but also on the value of the second controller.

In single control agent queue case, the control signal applied by the control agent anywhere in the queue to control the queue is given by Equation (13) which is also applicable for queues having multiple sub queues if the interaction between sub queues is considered [21]. Hence, Equation (16) can be used to obtain the control signal for any case.

$$
u^{1}[k]=-\frac{a_{n^{*}}^{\overline{u^{1}}}\left[k+\boldsymbol{n}^{*}\right]}{a_{\boldsymbol{n}^{*}}^{u^{1}}\left[k+\boldsymbol{n}^{*}\right]}, \quad u^{2}[k]=-\frac{a_{\boldsymbol{n}^{*}+1}^{\overline{u^{2}}}\left[k+\boldsymbol{n}-\boldsymbol{n}^{*}\right]}{a_{\boldsymbol{n}^{*}+1}^{u^{2}}\left[k+\boldsymbol{n}-\boldsymbol{n}^{*}\right]} \quad \mathrm{k} \geq 0, \boldsymbol{n}^{*} \approx \frac{\boldsymbol{n}}{\mathbf{2}}
$$

According to Equation (11), the control signal is related to the state of the entire queue. Thus, the prestige and value of the right most agent can be deduced from other control agents. Another approach used for the analysis of queue is by using inductive process. In this process, if the action of right most agent is forced to become zero, the action of the other agents approach zero through induction. But in sub queues, the process is slightly different. In the left most sub queue, the left most control agent is forced to control the right most agent in the same sub queue only. If the left most control agent in left most sub queue, does not only control the right most agent in the same sub queue, the controllers cannot control the entire queue (according to inductive analysis). For example, the target agent of the queue $\left(\mathrm{X}_{0} \mathrm{O}_{1} \cdots \mathrm{O}_{\mathrm{n}}\right)$ had one neighbor but in this case the target agent $\left(\mathrm{O}_{\mathrm{n}^{*}}\right)$ has two neighbors $\left(\mathrm{O}_{\mathrm{n}^{*}-1}\right.$ and $\left.\mathrm{O}_{\mathrm{n}^{*}+1}\right)$ as shown in Figure 1. If there are two neighbors $\left(\mathrm{O}_{\mathrm{n}^{*}-1}\right.$ and $\left.\mathrm{O}_{\mathrm{n}^{*}+1}\right)$ for target agent $\left(\mathrm{O}_{\mathrm{n}^{*}}\right)$, one of neighbor $\left(\mathrm{O}_{\mathrm{n}^{*}+1}\right)$ must be other target of other controller $\left(\mathrm{X}^{2}\right)$ so that the attitude of $\mathrm{O}_{\mathrm{n}^{*}}$ approached zero [21-23].

$$
X^{1} O_{1} \cdots O_{n^{*}-1} O_{n^{*}} O_{n^{*}+1} \cdots O_{n} X^{2}
$$

Figure 1. Induction assumption for two controllers [21]

The aim of this work is to show how social changes are handled in a crowd using graph theory. The control agent had only one target that is unrealistic in many social setting. Therefore, in the next scheme, multiple control agents are introduced in crowd to stabilize a two dimensional crowd. The controllers use cooperation and communication to achieve a common objective [23].

\subsection{Multi-Agent Controllers to Stabilize Two-Dimensional Crowd}

In a two dimensional crowd, cooperative control system is applied. The cooperative system consists of dynamic objects that cooperate and communicate to achieve a shared or common goal. Illustrations of cooperative system are understood in majority of human acting and other biologic systems that are considered to have certain advantages over other cooperative control systems [29-30]. A few examples of cooperative control systems are economic and social systems [31-33]. Cooperative control theory has been applied to stabilize the attitude of the crowd [23]. In this method, a two-dimensional (2D) suggestible crowd was assumed. The law used for controlling the agents was similar to previous works. Following is the list of assumptions used in that analysis: 1) Control agents (X) had one neighbor, 2) Control agents had exactly one target. Thus, the number of targets equaled with the number of control agents in the crowd, 3) At least one path must exist from position of control agent to its target, 4)

TELKOMNIKA Vol. 15, No. 2, June 2017 : 763 - 770 
Communication among control agents had not delay, 5- the full state of the crowd can be sense by control agent and the control target should be close to controller [23].

In that approach, the assumptions were used to create laws for algorithms. The first law forced the controllers to achieve zero action. Based on this law, if two controllers $\left(\mathrm{X}^{\mathrm{i}}, \mathrm{X}^{\mathrm{j}}\right)$ had targets consequently $\mathrm{T}^{\mathrm{i}}$ and $\mathrm{T}^{\mathrm{j}}$, the distance of control $\mathrm{X}^{\mathrm{i}}$ relative to its target $\left(\mathrm{T}^{\mathrm{i}}\right)$ must be less than the distance of other controller $\left(\mathrm{X}^{\mathrm{j}}\right)$ relative to $\mathrm{X}^{\mathrm{i}}$ 's target $\left(\mathrm{T}^{\mathrm{i}}\right)$. The target elements were considered to belong to set $\Omega_{0}$. In the algorithm, the neighbors of target set were determined, with the condition that only are neighbor has non zero action, otherwise, the laws fail to control the system. In reality, the inductive approach was applied [21-22].

In this algorithm, the element of new set $\left(\Omega_{\alpha}\right)$ must have only one neighbor who has non-zero action, So that the action of new neighbor can approach zero. This process continues until all the neighbours before thwe next control agent become zero. The last set is called $\Omega_{\infty}$. The next algorithm is related to stabilizing time. This algorithm states that maximum stabilization time is reached when the distance between control agents is maximums. This method was limited by the condition that crowd must have less control agents than observers. This method is improved using graph theory. It is assumed the first assumption used in the previous study is unrealistic in some social stings, which must be investigated in future studies, the stabilizing time must be improved, based on the number of observers. It should include recent psychological studies and the social interaction of the crowd must be optimized. Discrete systems were also studied [34] for digital control systems that can be useful for stabilization of crowd's action in psychological model. Le Bon's theory has also been studied by some researchers [35].

\section{Conclusion}

This paper presents an inclusive review on the psychological crowd based on LeBon's theory and control schemes for stabilizing the attitude of crowds such as one-dimensional and two-dimensional crowds. The vast number of available references showed that LeBon's theory has a lot of applications for the irrational crowd model that is used by sociologists and psychologists. The best control scheme introduced control agents, who propagated their behavior based on the whole state of psychological crowd. These control agents were compatible with social group behavior theories such as LeBon's theory. The previous works attempted to compute the control signal values for various positions of control agents based on the mathematical psychological crowd model and reduced the burden of control agents. It is valuable to study more about recent social psychological theories and graph theories to improve modeling and controlling of psychological crowd model.

\section{Acknowledgements}

The authors would like to thank Universiti Teknologi Malaysia and the Ministry of Higher Education for their supports. This project is supported by Research University Grant Vote $13 \mathrm{H} 78$.

\section{References}

[1] Vider S. Rethinking crowd violence: Self categorization theory and the Woodstock 1999 riot. Journal for the Theory of Social Behaviour. 2004; 34(2): 141-166.

[2] Le Bon G. The crowd: A study of the popular mind. Fischer. 1897.

[3] Smelser NJ. Theory of collective behavior. Quid Pro Books. 2011.

[4] Moscovici S. The age of the crowd: A historical treatise on mass psychology. Cambridge University Press. 1985.

[5] Drury J, Reicher SD, Stott C. The psychology of collective action. Culture and Social Change: Transforming Society Through the Power of Ideas. 2012; 19.

[6] Bergey K, Spieser K, Davison DE. The psychological dynamics of students in a classroom: Modeling and control strategies based on suggestibility theory. 2007 IEEE International Conference on Control Applications. 2007.

[7] Sadiyoko A, Riyanto TB, Mutijarsa K. The Propagation of Psychological Variables in Crowd: Simulation Results. 2012 Sixth Asia Modelling Symposium. 2012. 
[8] Mahalleh VBS, Selamat H, Sandhu F. The effects of distance in dynamic psychological factors of onedimensional queue. Control Conference (ASCC), 2015 10th Asian. 2015.

[9] Wood S. Prestige in world politics: History, theory, expression. International Politics. 2013; 50(3): 387411.

[10] Drury J, Reicher S. Collective action and psychological change: The emergence of new social identities. British Journal of Social Psychology. 2000; 39(4): 579-604.

[11] Khamis N, Haniff MF, Selamat H, Lutfy OF. Agent motivational and repulsion forces optimization in agent basic movement model. Control Conference (ASCC), 2015 10th Asian. 2015.

[12] Spears R, Postmes T. Group Identity, Social Influence, and Collective Action Online. The Handbook of the Psychology of Communication Technology. Oxford: John Wiley \& Sons. 2015: 23-46.

[13] Festinger L, Pepitone A, Newcomb T. Some consequences of de-individuation in a group. The Journal of Abnormal and Social Psychology. 1952; 47(2S): 382.

[14] Diener E. Deindividuation: The absence of self-awareness and self-regulation in group members. The psychology of group influence. 1980; 209-242.

[15] Prentice-Dunn S, Rogers RW. Deindividuation and the self-regulation of behavior. Lawrence Erlbaum Associates, Inc. 1989.

[16] Zimbardo PG, editor. The human choice: Individuation, reason, and order versus deindividuation, impulse, and chaos. Nebraska symposium on motivation. 1969.

[17] Ohlberg M. The Era of Crowds: Gustave Le Bon, Crowd Psychology, and Conceptualizations of MassElite Relations in China. The Dynamics of Transculturality. 2015: 157-183.

[18] Stage C. The online crowd: a contradiction in terms? On the potentials of Gustave Le Bon's crowd psychology in an analysis of affective blogging. Distinktion: Scandinavian Journal of Social Theory. 2013; 14(2): 211-226.

[19] Reicher S. The psychology of crowd dynamics. Blackwell handbook of social psychology: Group processes. 2001: 182-208.

[20] La Macchia ST, Louis WR. Crowd behaviour and collective action. Understanding Peace and Conflict Through Social Identity Theory. 2016: 89-104.

[21] Spieser K, Davison DE. Multi-agent stabilisation of the psychological dynamics of one-dimensional crowds. Automatica. 2009;45(3):657-64.

[22] Spieser K, Davison D. Stabilizing the psychological dynamics of people in a queue. 2008 American Control Conference. 2008.

[23] Spieser K, Davison D. A cooperative multi-agent approach for stabilizing the psychological dynamics of a two-dimensional crowd. 2009 American Control Conference. 2009.

[24] Nunes DS, Zhang P, Silva JS. A survey on human-in-the-loop applications towards an internet of all. IEEE Communications Surveys \& Tutorials. 2015; 17(2): 944-965.

[25] Irfan MT, Ortiz LE. On influence, stable behavior, and the most influential individuals in networks: A game-theoretic approach. Artificial Intelligence. 2014; 215: 79-119.

[26] Cazenille L, Bredeche N, Halloy J. Automated optimisation of multi-level models of collective behaviour in a mixed society of animals and robots. 2016.

[27] Casadiego L, Pelechano N, editors. From One to Many: Simulating Groups of Agents with Reinforcement Learning Controllers. International Conference on Intelligent Virtual Agents. 2015.

[28] Peters RS. Authority, responsibility and education. Routledge. 2015.

[29] Akçay E, Roughgarden J, Fearon JD, Ferejohn JA, Weingast BR. Biological institutions: The political science of animal cooperation. 2013.

[30] Rey GZ, Carvalho M, Trentesaux D. Cooperation models between humans and artificial selforganizing systems: Motivations, issues and perspectives. Resilient Control Systems (ISRCS), 2013 6th International Symposium on. 2013.

[31] Xargay E, Dobrokhodov V, Kaminer I, Pascoal AM, Hovakimyan N, Cao C. Time-critical cooperative control of multiple autonomous vehicles. IEEE Control Systems Magazine. 2012; 32(5): 49.

[32] Sandhu F, Selamat H, Mahalleh VBS. Direct Yaw Control of Vehicle using State Dependent Riccati Equation with Integral Terms. Advances in Electrical and Computer Engineering. 2016; 16(2).

[33] Sandhu F, Selamat H, Mahalleh VBS. Review of Modern Vehicle Modelling. Journal of Telecommunication, Electronic and Computer Engineering (JTEC). 2016; 8(11): 111-117.

[34] Shams NA, Davison DE, editors. A co-operative control approach to the regulation of nonlinear discrete-time structured systems. Electrical and Computer Engineering (CCECE), 201124th Canadian Conference on. 2011.

[35] Mahalleh VBS, Selamat H, Sandhu F, Khamis N. Improved crowd psychological model and control. Jurnal Teknologi. 2016; 78(6-13): 121-128. 